\title{
The Effect of $E$. Coli Endotoxin on the Developing Rat Liver. II. Immunohistochemical Localization of Alpha-Fetoprotein in Rat Liver Multinucleated Giant Cells
}

\author{
J. M. ANDRES, ${ }^{(22)}$ B. R. DARBY, AND W. A. WALKER \\ Department of Pediatrics (Gastroenterology), University of Florida College of Medicine, Gainesville, Florida \\ [J.M.A., B.R.D.], and Department of Pediatrics, Harvard Medical School, and the Children's Services (Pediatric \\ Gastroenterology), Massachusetts General Hospital, Boston, Massachusetts [W.A.W.]
}

\begin{abstract}
Summary
Immunoperoxidase histochemical staining techniques have been used previously to localize alpha-fetoprotein (AFP) in hepatocytes from rat and human liver tissues. In this study, we extended these observations by examining liver tissues from rat fetuses exposed to $E$. coli endotoxin in order to document the presence of AFP in hepatic multinucleated giant cells. Liver sections were examined under light microscopy after incubation with purified antibody-peroxidase conjugates and histochemical stains. These sections showed a positive reaction for AFP in giant cells and hepatocytes that appeared as granular, brown intracytoplasmic deposits in cells throughout the hepatic lobule. Furthermore, a direct correlation was found between the number of positively stained giant cells and the serum concentration of AFP. The findings demonstrated that AFP distribution in endotoxin-induced liver injury is confined to isolated hepatocytes and multinucleated giant cells. This observation provides evidence that the origin of the giant cell in toxin-exposed fetal rat liver may be the hepatocyte.
\end{abstract}

\section{Abbreviations}

AFP, alpha-fetoprotein

PAP, peroxidase-anti-peroxidase

PBS, phosphate buffered saline

RER, rough endoplasmic reticulum

The synthesis of AFP by hepatocytes during normal ontogeny has been studied carefully $(6,13)$; however, the cellular basis for increased AFP production after liver injury during fetal development, or during the postnatal period, is still an unanswered question. We have previously demonstrated elevated levels of serum AFP and hepatic giant cell induction in Sprague Dawley fetal rats injected with $E$. coli endotoxin (2). In addition, increased leucine incorporation into AFP from the endotoxinexposed rats suggested accelerated synthesis of AFP by the perturbed fetal rat livers. These giant multinucleated cells contain glycogen; show proliferation of lysosomes; and possess a RER, or potential for cellular protein metabolism (17). This latter feature of the giant cell raised a question about its unresolved histogenesis. In the present study, we report the results of a histochemical experiment designed to examine the cellular localization of AFP in the liver tissue of these endotoxin-treated fetal rats. The findings show that AFP distribution is confined to hepatocytes and multinucleated giant cells.

\section{MATERIALS AND METHODS}

Timed-pregnant (16-day) Sprague Dawley rats were obtained from Charles River Breeding Labs (Wilmington, MA) and subjected to ether anesthesia and laparotomy. According to methods described previously (2), the fetal amniotic sacs were then exposed and injected with endotoxin (Bactolipopolysaccharide $E$. coli 055:B5, Difco Laboratories, Detroit, MI) in a concentration of $0.003 \mu \mathrm{g} / \mathrm{ml}$ with $30 \mu \mathrm{l}$ as the standard injection dose. The abdominal cavity of the pregnant animals was then closed. Five days later, the fetuses were surgically removed and liver was obtained for histologic sections. The rat fetuses were killed by decapitation and serum was obtained for AFP concentrations. The endotoxin-perturbed fetal livers were microscopically abnormal because of the presence of numerous multinucleated giant cells, parenchymal round cell infiltration, and hepatocyte membrane damage with marked cellular vacuolation. Ninetyfive percent cold ethanol containing $1 \%$ glacial acetic acid was discovered to be the most suitable fixation system for retention of AFP antigenicity. Liver tissues were then dehydrated in absolute ethanol, cleared through xylene and embedded in paraffin. Five-micron thick serial sections were cut at room temperature, deparaffinized in xylene, cleared in absolute ethanol, and rinsed in PBS at $\mathrm{pH}$ 7.4. Sections were mounted on serially numbered, clean, uncoated slides.

Antibodies directed against rat AFP were produced in rabbits according to techniques previously described (21). Purified rat AFP was prepared by vertical polyacrylamide gel electrophoresis of amniotic fluid from 16-day-old rat fetuses. Proteins migrating to the location of standard AFP (kindly provided by Elliot Alpert, M.D., Massachusetts General Hospital, Boston, MA) were separated by microtome slicing and extracted in $10 \mu \mathrm{l}$ of PBS. Rabbits were injected subcutaneously with purified AFP mixed with Freund's adjuvant (Difco Pharmaceutical Co., Detroit, MI) and subsequently boosted at $4-w k$ intervals. The monospecificity of the rabbit antirat AFP was confirmed by double gel diffusion against amniotic fluid and standard rat AFP; single precipitation lines of identity were obtained between antiserum and amniotic fluid or standard AFP.

Immunohistochemical detection by the PAP unlabeled antibody-enzyme technique according to Sternberger (19) was achieved using the following steps: $(I)$ endogenous peroxidase activity was blocked by immersing sections in a fresh $0.5 \%$ solution of hydrogen peroxide in methanol for $30 \mathrm{~min}$; (2) to further reduce non-specific background staining, the liver sections were incubated in a humid chamber for $30 \mathrm{~min}$ with normal goat serum (Microbiological Associates, Bethesda, MD) diluted 
1:10 in PBS; (3) rabbit-antirat AFP-antiserum was applied to the sections at various dilutions ranging from $1: 10$ to $1: 2500$ for 30 min; (4) goat-antirabbit IgG (Micro-biological Associates, Bethesda, MD) at 1:50 dilution was then applied for $30 \mathrm{~min}$; and (5) the sections were treated with rabbit-PAP (Cappel Laboratories, Cochranville, PA) diluted 1:50 in PBS for $30 \mathrm{~min}$. After each step, the slides were extensively rinsed with three changes of PBS, $\mathrm{pH} 7.4$, at room temperature. The reaction was visualized with 3-3'-diaminobenzidine tetrachloride (Sigma Chemical Co., St. Louis, MO; $0.05 \mathrm{M}$ tris-HCL buffer, $\mathrm{pH}$ 7.2) containing $0.01 \%(\mathrm{v} / \mathrm{v})$ hydrogen peroxide (Fisher Scientific, Orlando, FL) for $5 \mathrm{~min}$. Sections were counterstained with hematoxylin, dehydrated with various concentrations of alcohol, cleared with xylene and mounted in Permount (Fisher Scientific, Orlando, FL). Liver sections, treated with normal pooled rabbit serum or with PBS, served as controls. At the time of animal sacrifice to obtain liver tissue, serum was obtained for AFP determination by electroimmunodiffusion (10) in $1 \%$ agarose containing sodium barbital buffer ( $\mathrm{pH} 8.6$ ) and rabbit AFP antibody.

\section{RESULTS}

Figures 1 and 2 show representative sections of fetal liver after $E$. coli endotoxin exposure and incubation with the 1:2500 dilution of AFP antiserum and non-immune control serum. Liver tissue fixed with $95 \%$ ethanol and glacial acetic acid was necessary to retain antigen determinants of AFP for immunohistochemical detection by the PAP-unlabeled antibody method. At the dilute antibody concentration, the background staining was minimal and the positive reaction for AFP consisted of a coarse, granular-brown intracytoplasmic deposit localized within giant cells and isolated hepatocytes randomly distributed in the liver lobule. The perinuclear area of the giant cell was more densely stained than the remaining cytoplasm (Fig. 2). All controls gave negative results. The number of AFP-positive giant cells was then determined in each liver specimen and related to the concentration of serum AFP in the corresponding rat fetus
(Fig. 3). There was a positive correlation between the number of giant cells per square millimeter and the serum concentration of AFP, with a correlation coefficient of $0.57(\mathrm{P}<0.005)$.

\section{DISCUSSION}

The origin and the mechanism of formation of multinucleated giant cells are unclear. Crain and Landing (3) hypothesized that dissolution of intercellular membranes resulted in fusion of hepatocytes. After stimulation by murine hepatitis virus, macrophages in tissue culture have been shown to fuse without demonstration of autoradiographic evidence for DNA synthesis (9). In this regard, the giant cells found in liver tissue have not as yet been characterized as proliferating, DNA synthesizing cells by the standard techniques of thymidine incorporation or autoradiography. Amitotic division, or cellular growth with nuclear fragmentation secondary to mitotic inhibition of young proliferating hepatocytes, is another proposed mechanism to explain giant cell formation (14).

Interestingly, Sutton and Weiss (20) described cellular transformation of non-replicating blood monocytes in tissue culture which changed sequentially into macrophages, epithelioid cells, and multinucleated giant cells; the proposed fusion of epithelioid cells to form giant cells almost always occurred near discharging lysosomes thus suggesting that hydrolytic enzymes may be required for membrane changes associated with cell fusion. Recently, it was demonstrated that peripheral blood monocytes fuse and form multinucleated giant cells in response to soluble factors elaborated by antigen- or T-cell-mitogen-stimulated human lymphocytes (15). To our knowledge, there is no experimental evidence to suggest that $T$ and $B$ cells undergo transformation to larger multinucleated cells even though endotoxin may be mitogenic for activated T-lymphocytes (1) and B-lymphocytes (5).

Our fetal rat study made use of peroxidase-labeled histochemical probes for early AFP detection in liver tissue. We discovered that hepatic giant cells contain AFP; hence, the origin of these multinucleated cells could be hepatocytes. Fetoprotein has also
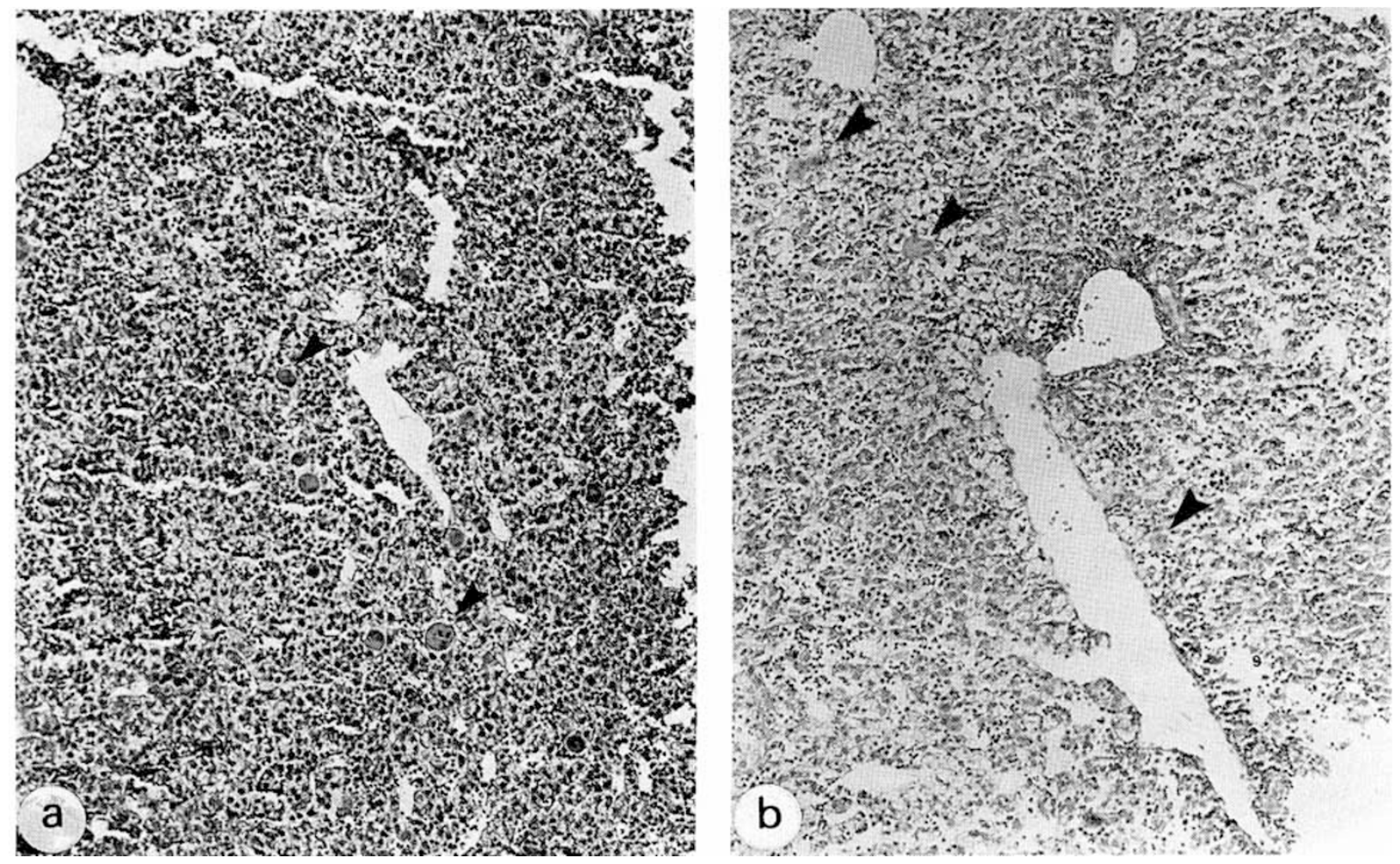

Fig. 1. Fetal rat liver tissue after exposure to intra-amniotic endotoxin. Magnification, $\times 100$. (a) Specific immunohistochemical staining for AFP using rabbit-anti-rat AFP and (b) Background using non-immune rabbit serum. AFP, alpha-fetoprotein. Note giant cells (arrows). 

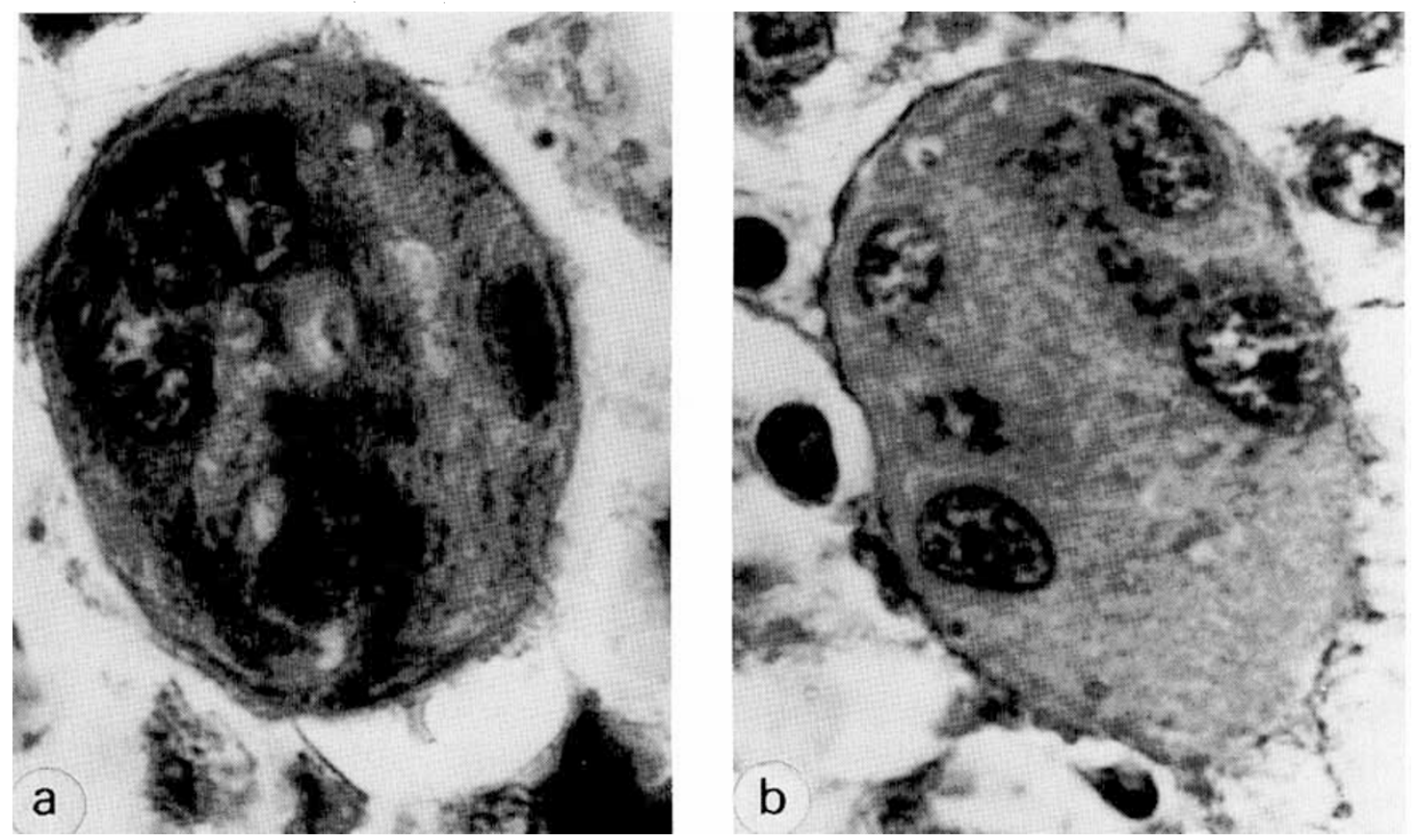

Fig. 2. Fetal rat liver tissue after exposure to intra-amniotic endotoxin showing a single giant multinucleated cell. Magnification, $\times 1000$. $(a)$ Immunohistochemical stain with perinuclear accentuation of AFP and $(b)$ Background using non-immune rabbit serum. AFP, alpha-fetoprotein.

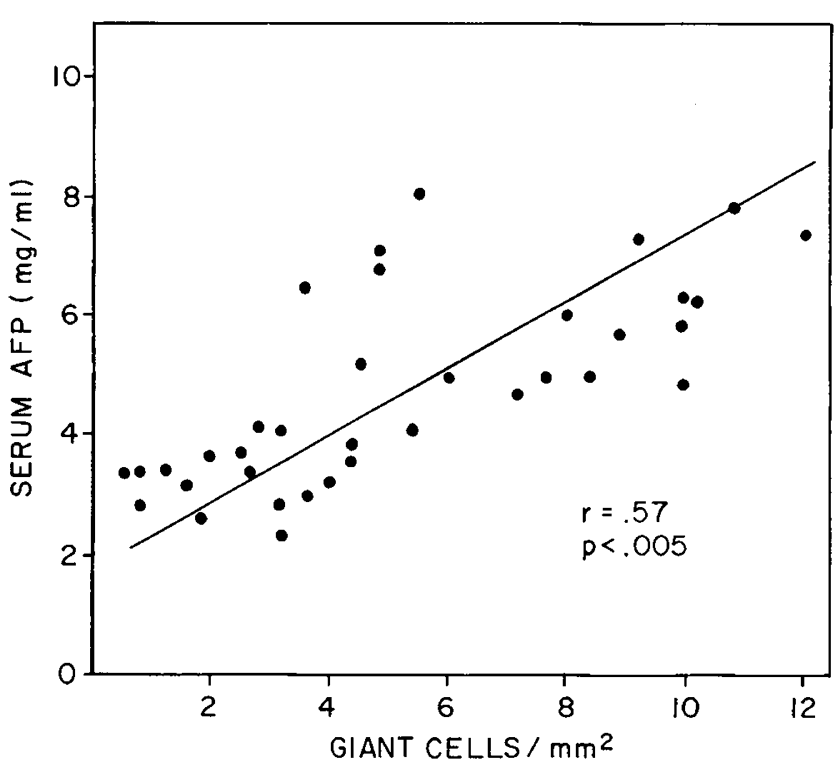

Fig. 3. Scattergram showing the relationship of serum AFP $(\mathrm{mg} / \mathrm{ml})$, to the number of giant cells (per $\mathrm{mm}^{2}$ ). AFP, Alpha-fetoprotein.

been detected in hematopoietic precursor cells using immunofluorescent techniques; artifact or phagocytosis by cells such as monocytes or megakaryocytes might account for these fetoprotein-positive cells (16). Diffusion of proteins into cells may occur when frozen sections are prepared before fixation, or if tissues are fixed in alcohol-acetic acid with stirring (7). Immunolocalization artifact cannot be ruled out absolutely for our study because we utilized alcohol-acetic acid as a fixative, but freezing and stirring were not part of the tissue preparation.

In the present study, the prominent, more densely-stained perinuclear cytoplasm of the giant cell was similar to the results of previous AFP localization studies for protein in fetal rat livers. In a horseradish peroxidase histochemical experiment Nayak et al. (12) described this characteristic location of AFP for normal fetal hepatocytes; and in a chemical-induced rat hepatoma study, AFP was localized in the perinuclear space, RER, and Golgi apparatus (8). The results of other experimental carcinogenesis studies involving the liver suggest that AFP is produced by the oval cell, presumably a transitional cell between liver precursor cell and fetal hepatocyte $(4,18)$. A direct correlation may be found between serum AFP concentration and the number of oval cells (18), or the number and staining intensity of all AFPcontaining cells $(13,11)$. After $E$. coli endotoxin hepatic injury, we noted that serum AFP was directly proportional to the number of giant cells, although no attempt was made to quantitate the number and staining intensity of AFP-positive fetal hepatocytes. Furthermore, oval cells were not recognized in the endotoxin-perturbed fetal rat livers; to our knowledge, a relationship between this transitional cell and the giant cell has not been reported.

\section{REFERENCES AND NOTES}

1. Andersson, J., Moller, G., and Sjöberg, O.: Selective induction of DNA synthesis in T and B lymphocytes. Cell. Immunol., 4: 381 (1972).

2. Andres, J, and Walker, W. Effect of Escherichia coli endotoxin on the developing rat liver. I. Giant cell induction and disruption in protein metabolism. Pediatr. Res., 13: 1290 (1979).

3. Craig, J. and Landing, B.: A form of hepatitis in the neonatal period simulating biliary atresia. Arch. Pathol., 54: 321 (1952)

4. Dempo, K., Chisaka, N., Yoshida, Y., Kaneka, A., and Onoe, T.: Immunofluorescent study on alpha-fetoprotein producing cells in the early stage of 3'-methyl-4-dimethyl-aminobenzine carcinogenesis. Cancer Res., 35: 1282 (1975).

5. Forbes, J. T., Nakao, Y., and Smith, R. T.: T mitogens trigger LPS responsiveness in mouse thymus cells. J. Immunol., 114: 1004 (1975).

6. Gitlin, D., Pericelli, A., and Gitlin, G. M.: Synthesis of $\alpha$-fetoprotein by liver, yolk sac and gastrointestinal tract of the human conceptus. Cancer Res., 32: 979 (1972).

7. Guillouzo, A., Belanger, L., Beaumont, C., Valet, J. P., Briggs, R., and Chiu, J. F.: Cellular and subcellular immunolocalization of $\alpha$-fetoprotein and albumin in rat liver: Reevaluation of various experimental conditions. J. Histochem. Cytochem., 26: 948 (1978).

8. Kuhlmann, W. D.: Ultrastructural detection of alpha-fetoprotein in hepatomas by use of peroxidase-labeled antibodies. Int. J. Cancer, 22: 335 (1978).

9. Laufs, R.: The formation of giant cells in mouse macrophage cultures infected with mouse hepatitis virus (MHV-3). Virchows Arch. (Pathol. Anat.), 342; 169 (1967).

10. Laurell, C.: Quantitative estimation of proteins by electrophoresis in agarose gel containing antibodies. Ann. Biochem., 15: 45 (1966).

11. Mohanty, M., Das, P. K., Mittal, A., and Nayak, N.: Cellular basis of induced $\alpha$-fetoprotein synthesis by hepatocytes of adult mouse after hepatotoxic 
injury and partial hepatectomy. Int. J. Cancer, 22: 181 (1978).

12. Nayak, N., Das, P., Bhuyan, U., and Mittal, A.: Localization of $\alpha$-fetoprotein in human and rat fetal livers: An immunohistochemical method using horseradish peroxidase. J. Histochem. Cytochem., 22: 4 (1974).

13. Nayak, N. and Mittal, I.: The dynamics of $\alpha$-fetoprotein and albumin synthesis in human and rat liver during normal ontogeny. Am. J. Pathol., 86: 359 (1977).

14. Oledzka-Slotwinska, H. and Desmet, V.: Morphologic and cytochemical study on neonatal liver "giant" cell transformation. Exp. Mol. Pathol., 10: 162 (1969).

15. Postlethwaite, A. E.. Jackson. B. K.. Beachey, E. H., and Kang. A. H.: Formation of multinucleated giant cells from human monocyte precursors: Mediation by a soluble protein from antigen and mitogen-stimulated lymphocytes. J. Exp. Med., 155: 168 (1982).

16. Purtilo, D. T. and Yunis, E. J.: Alpha-fetoprotein: Its immunofluorescent localization in human fetal liver and hepatoma. Lab. Invest., 25: 291 (1971).

17. Ruebner, B. and Miyai, K.: The pathology of neonatal hepatitis and biliary atresia with particular reference to hemopoiesis and hemosiderin deposition. Ann. N.Y. Acad. Sci., 3: 375 (1963).

18. Sell, S.: Distribution of $\alpha$-fetoprotein and albumin containing cells in the livers of Fischer rats fed four cycles of N-2-fluorenyl-acetamide. Cancer Res.. 38: 3107 (1978)

19. Sternberger, L., Hardy, P.. Cuculis, J.. and Meyer, H.: The unlabeled antibody enzyme method of immunohistochemistry: Preparation and properties of soluble antigen-antibody complex (horseradish peroxidase-antihorseradish peroxidase) and its use in identification of spirochetes. J. Histochem. Cytochem., 18: 315 (1970).

20. Sutton, J. and Weiss, L.: Transformation of monocytes in tissue culture into macrophages, epithelioid cells, and multinucleated giant cells. J. Cell. Biol., 28: 303 (1966).

21. Williams, C. A. and Chase, M. W.: Production of antisel ' $1 \mathrm{~m}$. In: Methods in Immunology and Immunochemistry, Vol 1. Preparation of Antigens and Antibodies. pp. 197-306 (Academic Press, New York, 1967).

22. Requests for reprints should be addressed to: Dr. J. M. Andres. Dept. of Pediatrics (Gastroenterology), Box J-296, J. Hillis Miller Health Center, University of Florida College of Medicine, Gainesville, FL 32610.

23. Supported in part by a University of Florida Sponsored Research Award.

24. Received for publication October 4, 1982.

25. Accepted for publication May 12, 1983

\section{Letter to the Editor}

\section{H. M. ROBINSON}

Tropical Metabolism Research Unit, University of the West Indies, Kingston, Jamaica

The excellent review by Brasel (1), "Endocrine Adaptation to Malnutrition" is a thorough attempt to look for generalities in a confusing field. It is possible that one of the points of confusion Brasel leaves unresolved contains within it information that may help to reduce the confusion, and suggests a need for greater liason between investigators.

Brasel points out that studies on growth hormone in malnutrition generally report high levels of this hormone, with exceptions, in cases where growth hormone levels were originally normal or diminished. The studies of Monckeberg et al. (2) and Robinson et al. (3) were cited. Both of these studies do more than this. Robinson et al. finds abnormally high growth hormone levels in malnourished children showing zero or negative weight gain. These levels are 2-5 times higher than during dietary treatment. Dietary treatment initiates the recovery or catch-up growth phase. Both Monckeberg et al. and Robinson et al. also report on growth hormone levels in children being treated for existing malnutrition.

Similar reports have been given by Beas et al. (4) and Godard (5). They point out that during treatment and/or recovery from protein-energy malnutrition, lower growth hormone values were found in children in whom growth rate was very slow [Robinson et al. (3) and Godard (5)] or in those in whom recovery was not yet initiated [Monckeberg et al. (2) Beas et al. (4)] and higher growth hormone levels were found in those showing satisfactory growth rates [Robinson et al. (3) and Godard (5)]. The administration of growth hormone to the children who were not growing significantly increased growth rates [Monckeberg et al. (2)]. At no time during the catch-up growth phase [Robinson et al. (3)] did the growth hormone levels approach the abnormally high values shown in the malnourished group.

Malnutrition is a state defined anthropometrically. As such it is a measure of an anthropometric state achieved and not the rate of change of nutritional status or growth. The results of Monckeberg et al. (2), Robinson et al. (3), Beas et al. (4) and Godard (5) indicate that this rate of change, shown during recovery, is significantly related to growth hormone levels.

It would help in the interpretation of all results on malnourished children if clinical status could be specified more precisely than is possible by currently accepted anthropometric classification schemes, or by traditional clinical divisions into named disease states. It would be illogical to ask that only growth rates should be given, although they are clearly important. It is also reasonable to assume that food intakes would be important determinants of hormonal profile, and also that patients can be not only recovering, but if studied early enough after the initiation of malnutrition, their hormonal profile may also reflect their rate of deterioration.

It is difficult to see how coherence can be obtained. Is it unreasonable to suggest a discussion among principal investigators is needed to agree on an ideal list of clinical data for any malnourished child studied, and to propose the requirement for a single archive where copies of such new data could be lodged by all investigators, and made accessible to all workers in the field, permitting more easily the detection of trends of the type reported by Monckeberg et al. (2), Beas et al. (4), Godard (5), and Robinson et al. (3)?

\section{REFERENCES AND NOTES}

1. Brasel, J.: Pediatr. Res., 14: 1299 (1980)

2. Monckeberg, F., Donoso, G., Oxman, S., Pak, N., and Meneghello, J.: Pediatrics, 31: 58 (1963)

3. Robinson, H., Cocks, T., Kerr, D., and Picou, D. In: 'Endocrine Aspects of Malnutrition'. Ed. L. I. Gardner and P. Amacher, 1973, 45-72.

4. Beas, F., Contreras, I., Maccioni, A., and Arenas, S.: Br. J. Nutr., 26: 169 (1971).

5. Godard, C.: In: 'Endocrine Aspects of Malnutrition'. Ed. L. I. Gardner and P. Amacher, 1973, 19-30.

\section{Response}

JO ANNE BRASEL

Harbor-UCLA Medical Center, UCLA School of Medicine, Torrance, California

I completely agree with Dr. Robinson that much of the difficulty in evaluating the data on growth hormone levels in malnutrition is related to the fact that the subjects are often in differing states of malnutrition and/or recovery. It would have been very helpful to me in my review if the types of additional information on the patients and their condition, which is mentioned in the letter, had been available. I can only support the proposal that investigators in the field develop a format for recording such data for the use of others with great enthusiasm. Good luck! 